\title{
REJECTIONISM ABOUT TRUTH
}

\author{
Matti Eklund \\ [published in Pedersen \& Wright (eds.), New Waves in Truth, Palgrave Macmillan]
}

\section{INTRODUCTION}

It often happens, for various reasons, that philosophers defend radical views which, first, are too radical to be plausible, and second, are such that a less radical and more plausible view would satisfy the underlying motivations. Here is a historical example. The logical positivists famously sought to eliminate traditional metaphysics by arguing that the statements metaphysicians make are meaningless because of being unverifiable. Much of the ensuing discussion concerned whether verifiability is really necessary for meaningfulness. But clearly, even if the logical positivists were wrong about this, they could still have a strong case for the elimination of metaphysics. For already if they could establish that the statements made by metaphysicians are unverifiable, they could argue for the pointlessness of the enterprise. If we cannot obtain good evidence for or against the statements of metaphysics, surely metaphysics is a pointless enterprise.

I will here argue that we find another instance of the same general phenomenon in the debate about truth. In the literature on truth, there is much focus on deflationism. Deflationists often say that somehow the whole content of 'true' is given by a schema like the disquotation schema

(DS) $p$ is true iff $p$

or the equivalence schema,

(ES) the proposition that $\mathrm{p}$ is true iff $\mathrm{p}$.

There are also variant formulations that are not schemabased. In general, deflationists hold that while superficially it appears that 'true' is a predicate, its semantic function is importantly different from that of ordinary predicates. Sometimes this is expressed in the 
slogan that truth is not a property. In what follows, I will use 'deflationism' as a label for the view that a characterization of 'true' along these lines is correct. This is a matter of regimentation. The label has sometimes been used somewhat more loosely.

I think deflationists defend a radical doctrine — and a problematic one- - where a less radical doctrine, which I will call (sophisticated) rejectionism, would satisfy the underlying motivations equally well. Roughly, this less radical doctrine is the doctrine that the only use we have for a truth predicate is expressive. What I will do here is to explain what this rejectionist view is, how it differs from deflationism, and how it satisfies the motivations underlying deflationism. I will not actually defend the rejectionist view. In fact, I believe it is false. All I want to argue is that much effort spent arguing for and against deflationism is better spent arguing for and against rejectionism.

\section{SOPHISTICATED REJECTIONISM}

In chapter five of his Spreading the Word, 'Realism and Variations', Simon Blackburn discusses, as the title indicates, alternatives to realism with respect to a given discourse. Most of the discussion is devoted to the kinds of alternatives one might expect: error theory, reductionism, and expressivism.

But early in the chapter, Blackburn brings up another alternative. It is brought up alongside error theory - the view that the atomic sentences within the discourse are uniformly untrue - under the heading of 'rejectionism'. Blackburn uses the epithet 'Kraut' to explain it. If someone calls a German-Franz - a Kraut, and I do not agree on the view on Germans which underlies the use of the epithet, what should I say about the truthvalue of this person's remark? One possibility is that should reject the remark as false. This is what I should do if 'Franz is a Kraut' means something along the lines of 'Franz is a German and on that account he is a fit object of derision', for the second conjunct here is false, and hence the whole conjunction is. But another option is to regard the remark as true, and find another kind of fault with it. Compare, Blackburn suggests, saying 'Franz is a German', with the last word said in a derisive tone of voice. Here what is said is true, but one would reject part of what is communicated by the tone of voice employed. Maybe 'Franz is a Kraut' is like that. That is what corresponds to the other form of rejectionism: truth is not denied, but deploying the vocabulary under 
consideration is found objectionable, for one reason or other. Henceforth let me reserve 'rejectionism' for this sort of view. It is at best unclear whether rejectionism thus understood is in opposition to realism, as Blackburn suggests it is, but rejectionism can be an important kind of view even if its proper home is not in discussions of realism/antirealism.

The question of what to say about Krauthood is hardly a burning issue. But Blackburn briefly suggests a more interesting application. Marxists have traditionally been against talk of rights. But how exactly should this be construed? The claim that there simply are no rights may sound too radical to be believable. It might be more reasonable for the Marxist to say that there are some rights, but disown some things that would be conveyed by saying so, much as I might agree that strictly, some people - the Germans - are Krauts but disown some things that would be conveyed by saying this. Or one might imagine someone who wants to reject the whole practice of evaluating using aesthetic vocabulary, on for example the ground that she takes aesthetic evaluations to be an expression of superficiality. She might not want to say 'nothing is beautiful', but rather 'while I concede that, if I have to use the concept of beauty at all, I have to agree that some things are beautiful, I do not think we should use this evaluative concept in evaluating the aspects of the world around us'.

So far all of the examples have had to do with evaluative discourse. But the 'rejectionist' strategy can be deployed elsewhere too. Consider metaphysics. Some metaphysicians employ notions which other theorists are skeptical of. For example, they speak of what is metaphysically fundamental or what is metaphysically natural or of which representations are the most ontologically perspicuous. Suppose that you are one of the skeptics. What should you then say about, say, metaphysical fundamentality? A suggestion of a traditional-Viennese — kind would be that 'metaphysically fundamental' is meaningless. But that is hardly plausible. Even if discourse about metaphysical fundamentality is somehow objectionable, it is certainly on the face of it disciplinedthose who employ the notion seem to be able to communicate successfully with each other-and this speaks against a charge of meaninglessness. An outright error theory might be problematic as well. It might be awkward to say that nothing is more fundamental than anything else. Much more attractive is to take a rejectionist line: allow 
that some things are more fundamental than others, but reject some implications that taking this would normally have-e.g. that this has a certain significance for philosophy; a certain 'depth'. The suggestion shouldn't sound strange by any means. All that the rejectionist about metaphysical fundamentality says is that although the expression 'more metaphysically fundamental than' has a nonempty extension, the notion it expresses just isn't particularly interesting. The view parallels the views we would have about many folk concepts. The concepts of, say, folk physics are hardly theoretically useful; yet they are neither meaningless nor empty. 'Metaphysically fundamental' is maybe not a folk concept. But it might be a theoretical concept used for bad reasons.

Compare also the debate over 'folk psychology'. Some theorists have emphasized that folk psychology is a theory, and they have further argued that it is a bad theory, which we do best in rejecting. From this they have drawn the conclusion that central predicates of folk psychology, like 'belief' and 'desire', are like 'phlogiston' in being true of nothing at all. There is of course a less radical but still important conclusion one might draw: that although there are beliefs and desires, these things aren't what we should focus on in the study of the mind. ${ }^{1}$

The nonevaluative examples differ in some respects from the evaluative examples. They do not, or do not as clearly, involve the unwanted conveying of an attitude. But in all the cases mentioned we are dealing with an expression that has application but whose use is anyway inadvisable.

Now, what has all this to do with truth? Well, many theorists have been skeptical of theoretical deployment of the concept of truth. They have thought, for good reasons or bad, that the concept (and cognate alethic or representationalist concepts such as the concepts of reference, or representation, or aboutness, or proposition, or fact) cannot bear the theoretical burden it gets assigned by some theorists. What should these skeptics say about truth? It is fairly obvious that they need not, and probably should not, say that 'true' is meaningless or empty. They can instead make the rather more humdrum claim that although 'true' of course is meaningful and nonempty, it ought not to be employed in serious theories. Call this view simple rejectionism.

\footnotetext{
${ }^{1}$ See the discussion in Stich (1996), pp. 34ff, where Stich — criticizing his earlier self — draws attention to the distinction I here draw attention to.
} 
Now, simple rejectionism about truth, as stated, is pretty clearly incorrect. For a truth predicate is necessary for certain expressive tasks, as is routinely pointed out. We need the truth predicate to express, e.g., what would be expressed by infinite conjunctions and disjunctions, and to make indirect assertions. Consider then instead sophisticated rejectionism — henceforth, 'rejectionism' for short—-the view that the sole reason to employ a truth predicate in serious theories is its expressive usefulness.

\section{COMPARISON WITH DEFLATIONISM}

It might sound as if rejectionism just is deflationism: for deflationists standardly emphasize that the only reason for having a truth predicate is that such a predicate is needed for expressive purposes. But importantly, deflationists go further. As mentioned above, they say for example that truth is fully characterized by the disquotation schema or the equivalence schema.

Deflationism faces well known problems, for instance concerning whether the deflationist's characterizations of the truth predicate really deliver everything that even a deflationist should want from a truth predicate. ${ }^{2}$ I will not here attempt to contribute to the discussion of criticisms of existing proposals already found in the literature. Suffice it to say that there are familiar problems with the various versions of the deflationist view.

I think many of the problems discussed simply can be sidestepped. I will argue that rejectionism of the kind characterized satisfies the philosophical motivations behind deflationism, while avoiding many of the important problems faced by deflationism. To stress, rejectionism does not entail deflationism: even if no predicate can have the semantics the deflationist ascribes to the truth predicate, the usefulness of a truth predicate can be exhausted by its expressive uses. If we focus on rejectionism, we put the spotlight where it should be: not on whether this or that deflationary characterization of a truth predicate is successful, but on what the theoretical (as opposed to merely expressive) uses of a truth predicate, if any, may be, and, more generally, on what it is for truth to have a nonexpressive role in theorizing.

\footnotetext{
${ }^{2}$ The literature on this is huge. Horwich (1990) and Field (1994) are two defenses of deflationism which contain useful summaries of the criticisms that can be raised. Gupta (1993) forcefully presents important criticisms of Horwich's brand of deflationism.
} 
In what follows, I will first (section IV) further illustrate the difference between rejectionism and deflationism through discussion of Hartry Field's views. Then (section V) I will more generally discuss supposed theoretical advantages of deflationism, and argue that rejectionism accommodates them. In section VI, I will discuss the intuitive motivation for deflationism, and argue that neither in this case do we have a consideration which supports deflationism but which fails to support rejectionism. In section VII, I will turn to a different sort of consideration — one we may call 'metaphysical' - sometimes adduced in favor of deflationism, having to do with the supposed impossibility of analyzing truth. Section VIII will discuss consequences for the debate over truth.

\section{FIELD'S DEFLATIONISM}

Consider, further to illustrate the distinction between deflationism and rejectionism, Hartry Field's (1994) discussion of deflationism. In that article, Field seeks to develop a deflationary notion of truth such that all work that the notion of truth can reasonably be expected to do can be done by this notion. The deflationary truth predicate Field is mainly concerned with — the 'pure disquotational' truth predicate—is characterized by the feature that for every utterance $u$ the person using the predicate understands, the claim that $\mathrm{u}$ is true, in this sense, is cognitively equivalent to $\mathrm{u}$ itself. ${ }^{3}$ (Where two expressions e and $\mathrm{e}^{*}$ are cognitive equivalent iff: for any two sentences $\mathrm{S}$ and $\mathrm{S}^{*}$ differing only in that where one contains e the other contains $e^{*}$ these two sentences are fairly directly inferrable from each other, setting aside quotation contexts and intentional attitude contexts.) As Field understands the pure disquotational truth predicate, it is what he calls use-independent: to call 'snow is white' true is not to attribute to this sentence or utterance a property it would not have had if speakers had used language differently. ${ }^{4}$

Now, Field could not reasonably take this to be what our ordinary truth predicate is like, and to stress, nor does he make any claim to this effect. But what should Field say about the ordinary truth predicate? By his own lights he should say that it is not deflationary. The ordinary truth predicate is not use-independent. If we had used 'red' for

\footnotetext{
${ }^{3}$ Field (1994), p. 250.

${ }^{4}$ Field (1994), p. 266.
} 
white things, 'snow is red' would have been true. ${ }^{5}$ It would be odd to insist that the ordinary language truth predicate is meaningless or empty. Does Field mean to suggest that the ordinary language truth predicate does not in fact satisfy relevant versions of the schemata the deflationist emphasizes? Hardly. ${ }^{6}$ What Field must hold is rather simply that the features of the ordinary language truth predicate which distinguish it from a properly deflationist predicate are not theoretically useful features.

This means that there is a claim to which Field is committed which is significant in its own right, independently of what success he may have in constructing a deflationist truth predicate: that the usefulness of the natural language truth predicate - or any predicate which can count as a truth predicate - is exhausted by its expressive use. One possible way to establish such a claim is to characterize a predicate that by design only can be of expressive use, and then argue that this newly characterized predicate would be useful in exactly the way that the natural language truth predicate, or any possible truth predicate, is. But even should such an argument fail, for instance because it is impossible to design a predicate like that envisaged, Field's underlying claim, concerning what a truth predicate is and is not useful for, need not be impugned.

The distinction between rejectionism and deflationism is important. Even if deflationism is false, that need not impugn rejectionism about truth. The basic question is that raised already by rejectionism: does the notion of truth serve any theoretical purpose other than an expressive one?

\section{ACCOMMODATING THE MOTIVATION FOR DEFLATIONISM}

In this section I will go through some of the important theoretical motivations for deflationism, and argue that they are not compelling.

\footnotetext{
${ }^{5}$ The question of use-independence is a question over whether the instances of (DS) are necessary or not. What is provided in the text is a quick argument to the effect that they are not, when the truth predicate employed is the ordinary one. A potential complication is that sentence truth can be held to be relative to a language. One can think that if we had used 'red' differently in appropriate ways we would have spoken a different language, were different sentences are true, but that doesn't negate that truths about the truth conditions of sentences in various languages are necessary.

Regardless of what, in general, can be said in favor of this strategy, it is not of much relevance when it comes to the question of whether Field's truth predicate is the ordinary one. For Field speaks of utterances, and while the truth of a sentence may be language-relative, the truth of an utterance is not. ${ }^{6}$ For example the semantic paradoxes present problems regarding these schemata. But the paradoxes present problems also for the claim that there can be deflationistically acceptable truth predicates satisfying these schemata.
} 
In the introduction to their coedited collection of essays on truth (1999), Blackburn and Keith Simmons discuss some motivations for deflationism. Here is one:

We talked of truth along with existence as reaching the heights of abstraction. When we approach these heights, the air becomes thin indeed. Perhaps it becomes too thin to support philosophical reflection at all. If we asked 'what is existence, in general?' many philosophers might suppose that we have gone too far, so that we might reasonably address the question of what the world must be like for stones or minds or penguins to exist, no entirely general question about 'what it is to exist' can be posed or addressed....And if this seems to be the right way to go here, it might also commend itself in the case of truth. Perhaps there is nothing in general to say about truth in general, although there will be things to say about particular truths....

This deflationary view denies that there is an issue of "the nature of truth in general'.

There are two ways to take this last remark. It can be taken either as definitional of deflationism, or to state a supposed consequence of deflationism, understood as the view that truth is somehow fully characterized by something like one of the above schemata. If understood the first way, one can of course have no quarrel with the reasoning. But as earlier, let me understand 'deflationism' the latter way.

While one can indeed see how a deflationist view, thus understood, can be employed to make sense of, and respect, the points mentioned, it should be obvious that a deflationist view is strictly not needed. Already the analogy with existence should give rise to doubts: for one may think that even if fully general questions of existence cannot be usefully addressed, it is unclear even what a deflationist view on existence analogous to the deflationist view on truth would be. It can perhaps be retorted that taking the notion of existence to be fully characterized by the standard introduction and elimination rules for the existential quantifier is, in the relevant sense, a deflationist view on existence: for it is a formal characterization, paralleling a schemabased characterization of the truth

\footnotetext{
${ }^{7}$ Blackburn and Simmons (1999), p. 2 f.
} 
predicate. But if so, just turn to other examples. If general questions about truth and existence are inadvisable, so are general questions about, say, keeping or having. 'Keep' and 'have' can occur in sentences of all sorts of kinds, and the idea of a general account of what keeping might be or what having might be is plainly ridiculous. But what might be a thesis about keeping or about having relevantly analogous to the deflationist's paradigmatic schemabased characterizations of truth?

Deflationism is also sometimes brought up in discussions of various nonfactualist theses, that is, theses to the effect that some discourse which on the face of it is factstating is not in fact so. Some nonfactualists note that sentences within the discourses they consider are ordinarily called 'true' and 'false', and say that the truth predicate in question is deflationary. But deflationism is hardly necessary for the nonfactualist. Obviously, the nonfactualist can in principle insist that all ordinary indicative sentences are truth-apt in the ordinary sense of 'true' without committing herself to some schemabased characterization of the truth predicate. All that she needs is that a sentence need not be understood as robustly fact-stating in order for it to be truth-apt. There are, to be sure, specific views on truth that are in conflict with such a claim. If truth is correspondence with the facts, where this is understood in a sufficiently robust sense, then if the nonfactualist's story about the role of the sentences of a particular discourse is correct, these sentences are not truth-apt, for it does not make sense to ask whether what is expressed by these sentences corresponds with the facts. But to conclude from this that the nonfactualist who wants to insist on truth-aptness needs deflationism is to take deflationism and the correspondence theory to exhaust the options. ${ }^{8}$

The truth predicate used in Davidsonian meaning theories illustrates the possibility I want to draw attention to. The relation between Davidsonian theories and deflationism is of course contested-I will return to the topic below-but let me here simply follow what Donald Davidson himself has said on the matter. On the one hand, Davidson holds that the truth predicate cannot be understood as deflationary. ${ }^{9}$ On the other hand, it is taken as given that the theory employs T-sentences also for sentences

\footnotetext{
${ }^{8}$ A complication in any discussion of these matters is that there is also the possibility of deflationism about fact talk: the possibility of insisting that ' $p$ ' and 'it is a fact that p' are trivially interchangeable. In a deflationary sense, all discourses are trivially fact-stating. What nonfactualism, properly understood, says is that not all discourses are fact-stating in a more demanding way.

${ }^{9}$ See his (1990).
} 
containing evaluative vocabulary. ${ }^{10}$ A Davidsonian truth predicate is nondeflationary yet allows for the truth-aptness of evaluative sentences, independently of the deeper issues raised by nonfactualism.

Another motivation for deflationism - one which in the literature has been of considerable importance-comes from considerations having to do with indeterminacy. The idea has been that indeterminacy, for example such as that which Quine's famous arguments point to, presents a serious problem for theories of truth which are not deflationary. ${ }^{11}$ Let me consider specifically the discussion in Field (1994).

Field brings up the question of "what determines that our word "or" or "not" or "some" makes the contribution to truth conditions that we assume it makes', and argues that while the non-deflationist, the 'inflationist', has three choices regarding what to say, none of them particularly happy, the deflationist has an easy answer. ${ }^{12}$ The inflationist can, Field says, either try to appeal to naturalistic facts which determine this, or say that we have here semantic indeterminacy, or try to appeal to non-naturalistic facts: and he argues against each option. (Field holds that semantic indeterminacy and non-naturalism are both implausible, and that the prospects of finding naturalistic facts that determine the contributions these expressions make to truth conditions are dim.) But the deflationist can appeal to the 'conceptual necessity' of the instances of the (DS), and, e.g., derive

(TF) ' $q$ or $r$ ' is true if and only if ' $q$ ' is true or ' $r$ ' is true

from the instances of (DS),

' $\mathrm{q}$ or $\mathrm{r}$ ' is true if and only if $\mathrm{q}$ or $\mathrm{r}$

' $\mathrm{q}$ ' is true if and only if $\mathrm{q}$

' $r$ ' is true if and only if $r$.

\footnotetext{
${ }^{10}$ As Davidson says in (1967), 'What is special to evaluative words is simply not touched' (p. 31).

${ }^{11}$ See e.g. Leeds (1978), McGee (1993), and Field (1994).

${ }^{12}$ Field (1994), p. 257.
} 
Field notes that the argument only helps us to the instances of (TF) but doesn't immediately yield the generalization we might have been after, and outlines how we can appeal to substitutional quantification to deal with this. ${ }^{13}$

My main concern with Field's argument is this. When, at the outset, we want to explain the truth of the instances of (TF), what we want to explain is the truth of these instances as stated in our language. But then the mere possibility of introducing a word 'true' which functions like the deflationist's truth predicate such that we can explain the truth of the instances of (TF) that we get when it is this 'true' that we employ doesn't help. Unless the deflationist's 'true' is our actual 'true' we are just changing the subject. And precisely Field's claim that the instances of (DS) are necessary when the deflationist's 'true' is employed presents a serious problem here: for the instances of (DS) of ordinary English do not appear necessary. (Witness: "if "white" had meant red, then "snow is white" wouldn't have been true, but snow would still have been white.') $)^{14}$

Now, Field later introduces a 'quasi-disquotational' truth predicate, designed to have the intuitive modal properties. If he could argue that the ordinary truth predicate is the quasi-disquotational one, he would have a reply to the first worry.

But there is a more serious concern nearby. All that is needed to explain the mere truth of the instances of (TF) is the truth of the instances of (DS) which Field appeals to. In order for there to be a problem for the non-deflationist, it must be that she can't help herself to the truth of those instances. But Field doesn't really explain why there would be a problem, and in fact there really isn't one. The non-deflationist can reason as follows. Even if it is indeterminate what the expressions in sentence S mean, and hence what in the world makes S true, I can know that ' $\mathrm{S}$ ' as I use it in my actual language is true if and only if S. The indeterminacy can be seen to be a matter of its being indeterminate which language I speak. Regardless, I can know that what I am thinking is true. Compare perhaps: Suppose that Jones's language is such that it is indeterminate whether 'green' is true of green things or red things. Jones can still think truly, for all $x$, 'green' is true of $x$ iff $x$ is green. It is just that if Jones's 'green' means red the content of the thought is one we would express by saying that Jones's 'green' is true of $\mathrm{x}$ iff $\mathrm{x}$ is red.

\footnotetext{
${ }^{13}$ Field (1994), p. 258f.

${ }^{14}$ Compare the criticism of McGee's argument from indeterminacy to deflationism in my (forthcoming).
} 
There is a different way that indeterminacy might be argued to cause trouble for the non-deflationist. I do not think this other argument is persuasive either, but let me anyway bring it up, primarily because it is useful to highlight the contrast between this argument and the argument just considered. The alternative argument is to the effect that alethic notions, truth and reference and their ilk, should occupy a central place in an account of meaning only if there are enough determinate facts about truth and reference. Compare perhaps: one can certainly accept Quine's (1960) argument for meaning indeterminacy and still believe that there are such abstract entities as meanings; one will only have to say that it is radically indeterminate how the symbols that we use are related to these meanings. But consistently with this, one can take Quine's argument to show that talk of these abstract entities is to be jettisoned in a serious theory of language; appeal to them will be idle. Similarly, one can take Quine's argument for the radical indeterminacy of reference to show that the notion of reference should be jettisoned in a serious theory of language; and one might think that if reference goes, truth goes too.

It should be clear that if a consideration like this is deemed persuasive-I will make some remarks on this later-then what it establishes in the first place is rejectionism; deflationism is not the immediate conclusion.

\section{THE INTUITIVE SUPPORT FOR DEFLATIONISM}

I have argued that rejectionism satisfies the theoretical motivations behind deflationism. But it can be protested that deflationism is not only motivated by its theoretical usefulness: it is also motivated by features truth talk intuitively has. When I say 'it is true that sea water is salty' I don't seem to say anything which goes substantively beyond what I say when I say 'sea water is salty'. A deflationist might appeal directly to this and not argue for her view by appealing to supposed theoretical advantages.

It is useful, when evaluating this claim, to distinguish between deflationist views taking sentences as truth bearers and deflationist views taking propositions as truth bearers.

Consider first a view of the former kind. It is not immediately plausible that instances of the schema "“S" is true iff S' are necessary, still less does it seem plausible 
that the sentences flanking the biconditional come to the same thing. Certainly, to bring up a point mentioned already earlier, it appears that if 'white' had meant red, 'snow is white' would not have been true, but snow would still have been white. This is not to say that this form of deflationism is a nonstarter: only that it lacks intuitive motivation.

Suppose then we are dealing with a deflationist view of the latter kind, taking propositions as truth bearers. Here the problem is different. If the intuition is that the truth attributions are redundant - that 'it is true that...' does not add anything to the bare 'p'the proper reply is that this simpleminded redundancy theory anyway is generally agreed to be false. ${ }^{15}$ If, by contrast, the intuition is that sentences of the form 'it is true that $\mathrm{p}$ iff p' are necessary and apriori-perhaps even conceptually true- the worry is that one can be a non-deflationist without denying this. For, e.g., a correspondence theorist will likely hold that sentences of the form ' $p$ iff it corresponds with the facts that p' are necessary and apriori. Contemporary deflationists sometimes rather emphasize how the instances of the relevant schema somehow exhaust the content of the notion of truth or are somehow explanatorily primitive. ${ }^{16}$ But once the view is this refined, it is doubtful that deflationism is primarily justified by speaker intuitions: do ordinary speaker intuitions really render verdicts on what exhausts the notion of truth, or on what is explanatorily prior?

\section{THE ANALYSIS OF TRUTH}

Approaching the issue of deflationism about truth via considering the theoretical usefulness of a truth predicate, as I have done here when urging that we should consider the possibility of rejectionism, will not seem odd to those who come to deflationism from the philosophy of language literature. But for others-typically, those for whom the debate over truth primarily is an issue in metaphysics - it might seem strange. These theorists may urge that the case for deflationism proceeds as follows: Either truth is analyzable in more primitive terms or it is itself primitive, unless, by deflationism, the whole issue of the nature of truth is dissolved. The failure of the traditional theories of truth - the correspondence theory, the coherence theory, and the identity theory-shows

\footnotetext{
${ }^{15}$ For a summary of problems, see e.g. Soames (1997), pp. 5-12.

${ }^{16}$ See Armour-Garb and Beall (2005a), p. 3.
} 
that truth is not analyzable. It is not compatible with a properly naturalist or physicalist outlook to take truth to be primitive. Deflationism is the only remaining option.

For present purposes, the specific details of the argument do not matter. One can imagine the intermediate conclusions being argued for in different ways. What is important for different purposes is that if this is how deflationism is argued for, then rejectionism will not be an acceptable fallback position. For the - supposed-problems with the alternative views rejected are independent of whether truth is taken to be a theoretically useful notion of not. So long as 'true' stands for a genuine property, questions about the nature of this property can be raised.

I will here have to be brief about the sort of outlook just considered. Let me just note that successful analyses-whether we conceive of these as conceptual analyses or real definitions of properties - are few and far between. So that we should not be able to come up with an analysis of truth is only to be expected. We have better learn to live with 'primitive' concepts or properties which do not seem metaphysically fundamental; or at least with there being no readily available means of analyzing non-fundamental properties. Strategies analogous to the deflationist's strategy with respect to truth will not always be available. There is something suspect about the very strategy of the argument canvassed. ${ }^{17}$

\section{RELEVANCE TO THE DEBATE OVER DEFLATIONISM}

I have here sought to distinguish rejectionism and deflationism, and to give reasons for why the debate ought to be focused on rejectionism rather than deflationism. Now, of course questions about the theoretical or explanatory role of truth have not been absent from the debate. It is generally held that deflationism entails that truth cannot play a theoretical or explanatory role but can play only an expressive role. So one recognized way of arguing against deflationism is to argue that truth in fact has an theoretical role to play.

But emphasizing the distinction between rejectionism and deflationism helps show that rejectionism ought not merely to be discussed a consequence of deflationism: it

\footnotetext{
${ }^{17}$ Wright (1998) also argues that debates over truth are not most fruitfully construed as concerning analyses.
} 
can stand alone. And some prominent arguments for and against 'deflationism' look slightly different once the distinction between rejectionism and deflationism is clear. I have already discussed this in the case of indeterminacy. One can try to argue for deflationism based on indeterminacy in the way Field does. Or one can argue for rejectionism based on indeterminacy by arguing that if reference facts are as indeterminate as the indeterminacy arguments seem to show, the notion of reference cannot play an important theoretical role, and if reference cannot play such a role, truth cannot either.

Certain other well known issues are also cast in a slightly different light once rejectionism and deflationism are cleanly distinguished.

Take the familiar Shapiro-Ketland argument against deflationism. ${ }^{18}$ The argument starts with the observation that the deflationist takes truth to be 'insubstantial', and it is claimed that the deflationist therefore must hold that a theory of truth should be conservative. But the truth-theoretic extension of Peano arithmetic (PA) is nonconservative, whence truth is non-deflationary. Jeffrey Ketland (2005) also, more generally, emphasizes that he and Shapiro are concerned with the role of the notion of truth in the justification of reflection principles.

I do not want to try to evaluate the argument, only note the relevance of the present distinctions to it. Once we have distinguished rejectionism and deflationism, the argument splits into two. One argument is that the deflationist's characterization of the truth predicate entails that a theory of truth is conservative, something problematized by facts about the truth-theoretic extensions of PA. Another argument is that the nonconservativeness of the truth-theoretic extensions of PA—and more generally the usefulness of truth-theoretic extensions of PA-shows that the notion of truth is not merely of expressive use. These two arguments must be evaluated independently of each other. Volker Halbach (2001) argues on the deflationist's behalf that deflationists have not committed themselves to conservativeness of a theory of truth, and that it anyway is fairly immediate that theories of truth will not be conservative. Even if Halbach is completely right about this, it is a further question whether a non-conservative theory of truth is consistent with the claim that a truth predicate is only useful for expressive

\footnotetext{
${ }^{18}$ See e.g. Shapiro (1998) and Ketland (1999) and (2005).
} 
purposes. (Maybe it is consistent with this claim. All I want to stress is that the questions are different.)

Turn next to another familiar debate in the deflationism literature: that of whether deflationism is compatible with a Davidsonian meaning theory. Here again the question splits into two once we have the distinction between rejectionism and deflationism firmly in view. One question is whether the truth predicate in a Davidsonian meaning theory can be one characterized by a deflationist schema. Another question is whether the truth predicate in a Davidsonian meaning theory serves only an expressive function. Davidson has himself explicitly discussed the former question, and answered it in the negative. ${ }^{19}$ But even if Davidson is right about this, it is possible that the second question should be answered in the affirmative.

I am not the first to call attention to this possibility. Michael Williams (1999) in effect does so: while eschewing any attempt to define truth, he argues that the role of the notion of truth in a Davidsonian meaning theory is purely expressive. While Williams uses the label 'deflationism' differently from how I use it, it is clear how to put Williams' conclusion in the present terminology: while Davidsonian meaning theories are incompatible with deflationism, they are compatible with rejectionism. Claire Horisk (2007) criticizes Williams, emphasizing that deflationism delivers necessary Tbiconditionals while the T-biconditionals delivered by a Davidsonian meaning theory are contingent. Even if this is right, that only shows a conflict between Davidsonianism and deflationist characterizations of truth. A Davidsonian can still be a rejectionist.

Throughout this paper I have spoken about 'the theoretical role of truth'. But I have not said much about what it is for truth to have a theoretical role to play. I think the issue is actually rather murky. Consider some things that Richard Rorty (1986) and Williams (1999) say when motivating the claim that a Davidsonian theory is deflationist. Rorty says that on a Davidsonian theory, '...there is nothing more to be known about the relation between beliefs and the rest of reality than what we learn from a empirical study of causal transactions between organisms and their environment ${ }^{20}$ Williams says that what Davidson really does is to 'illuminate both meaning and truth by appeal to

\footnotetext{
${ }^{19}$ See Davidson (1990).

${ }^{20}$ Rorty (1986), p. 341.
} 
interpretation, an activity that can itself be understood without extensive theoretical resources'. ${ }^{21}$ One thing Rorty can seem to be saying is that facts about reference and truth supervene on other facts- 'naturalistic' facts, to use the label Rorty uses elsewhere in the article $^{22}$ - and therefore the notion of truth does not have an explanatory role. But such an inference is suspect. Are we to hold that nothing supervenient plays an explanatory role? In Williams, there is perhaps another suggestion: that we illuminate the concept of truth by relating it to an in some sense more basic concept of interpretation. But if this is supposed to support the claim that truth only has an expressive role to play one can again wonder about the inference: should we really say that every concept which can be reductively explained — or which can be implicitly defined by its role in a theory—only has an expressive role?

Adding to the confusion is the fact that another prominent deflationist, Field (1994), holds that if, on a given view, serious explanatory use is made of a predicate that is coextensive with the truth predicate, then the view in question is not deflationary.

Earlier I mentioned that even if there is no compelling argument from indeterminacy to deflationism, there can be a good argument from indeterminacy to rejectionism. Whether there is depends on how we conceive of the supposed role of truth. Some theorists, influenced by the defense of a correspondence theory in Field's early (1972) article - before Field turned to deflationism - seem to take an alethic approach to be bound up with the idea that there is a substantive reference relation, such as persuasive indeterminacy arguments might cast doubt on. The idea behind an alethic approach of this kind is to build on Tarski's characterization of truth in terms of reference and satisfaction, and then develop a physicalistically acceptable account of reference and satisfaction.

But an alethic approach need not be conceived of this way. Consider again Davidsonian theories. The arguments that Davidson and followers have marshaled for the view that a theory of meaning should take the form of a theory of truth are independent of how much determinacy there is, and Davidson himself positively revels in referential indeterminacy.

\footnotetext{
${ }^{21}$ Williams (1999), p. 320.

${ }^{22}$ Rorty (1986), p. 335.
} 
A different role of the notion of truth is in an account of assertion. Michael Dummett has suggested that truth is the aim of assertion, and that this fact can help elucidate assertion. Such a claim points to another way that the notion of truth can be central in a theory of language, compatibly with widespread indeterminacy of reference. It can be used in a theory of force, in Dummett's sense, even if it plays no role in semantics proper.

Furthermore, some theorists say that the notion of truth does not have a proper theoretical use, for an inferentialist approach, according to which the notion of correct inference is central to an account of meaning, is correct. But one may suspect that the notion of truth is needed in an elucidation of what distinguishes inferences from other transitions between thoughts. ${ }^{23}$ The notion can play the role of elucidating correct inference compatibly with widespread indeterminacy.

The rejectionist will have to deny that truth can play either role —or, more strictly, that it plays either role in a way that goes beyond its purely expressive function. Maybe such a denial can be made plausible. But appeal to indeterminacy is not sufficient to make it so.

\section{CONCLUDING REMARKS}

I have obviously not argued for rejectionism. To stress, I do not even subscribe to the view. All I have been concerned to argue is that this view is less radical than deflationism but satisfies all reasonable motivations behind deflationism. In a way this conclusion can even seem bland: I am not defending any particular view. But if I what I have argued is correct, then much of the debate about truth should shift its focus.

\section{REFERENCES}

Armour-Garb, B. \& Beall, JC. (eds.). (2005). Deflationary Truth. Chicago and La Salle, Illinois: Open Court.

Armour-Garb, B. \& Beall, JC. (2005a). Deflationism: The Basics. In Armour-Garb \& Beall (2005), pp. 1-29.

Blackburn, S. (1984). Spreading the Word. Oxford: Blackwell.

\footnotetext{
${ }^{23}$ Gupta (1993), p. 222.
} 
Blackburn, S. \& Simmons, K. (eds.). (1999). Truth. Oxford: Oxford University Press.

Davidson, D. (1967). Truth and Meaning. Synthèse, 17: 304-323. Reprinted in Inquiries into Truth and Interpretation (17-36). Oxford: Oxford University Press.

Davidson, D. (1990). The Structure and Content of Truth. Journal of Philosophy, 87: $279-328$.

Dummett, M. (1959). Truth. Proceedings of the Aristotelian Society, 59: 141-162.

Eklund, M. (forthcoming). The Ontological Significance of Inscrutability. Philosophical Topics.

Field, H. (1972). Tarski's Theory of Truth. Journal of Philosophy, 69: 347-375.

Field, H. (1994). Deflationist Views of Meaning and Content. Mind, 103: 249-285.

Field, H. (2000). Indeterminacy, Degree of Belief, and Excluded Middle. Noûs, 34: 1-30.

Gupta, A. (1993). A Critique of Deflationism. Philosophical Topics, 21/2: 57-81.

Reprinted with postscript in Armour-Garb and Beall (2005), pp. 199-233. Page

references are to the reprint.

Halbach, V. (2001). How Innocent is Deflationism? Synthèse, 126: 167-194.

Horisk, C. (2007) The Expressive Role of Truth in Truth-Conditional Semantics.

Philosophical Quarterly, 57: 535-557.

Horwich, P. (1990) Truth. Oxford: Blackwell.

Ketland, J. (1999) Deflationism and Tarski's Paradise. Mind, 108: 69-94.

Ketland, J. (2005) Deflationism and the Gödel Phenomena: Reply to Tennant. Mind, 114: $75-88$.

Kölbel, M. (2001). Two Dogmas of Davidsonian Semantics. Journal of Philosophy, 98: $613-635$.

Leeds, S. (1978). Theories of Reference and Truth. Erkenntnis, 13: 111-129.

McGee, V. (1993). A Semantic Conception of Truth? Philosophical Topics, 21: 83-111.

McGee, V. (2005). Inscrutability and its Discontents. Nô̂s, 39: 397-425.

Patterson, D. (2005). Deflationism and the Truth Conditional Theory of Meaning.

Philosophical Studies, 124: 271-294.

Quine, W.v.O. (1960). Word and Object. Cambridge, Mass.: MIT Press. 
Rorty, R. (1986). Pragmatism, Davidson and Truth. In E. Lepore (ed.), Truth and Interpretation: Perspectives on the Philosophy of Donald Davidson (333-368). Oxford: Blackwell.

Shapiro, S. (1998). Proof and Truth: Through Thick and Thin. Journal of Philosophy, 95: $493-521$.

Soames, S. (1997). The Truth About Deflationism. Philosophical Issues, 8: 1-44.

Stich, S. (1996). Deconstructing the Mind. Oxford: Oxford University Press.

Williams, M. (1999). Meaning and Deflationary Truth. Journal of Philosophy, 96: 54564.

Wright, C. (1998). Truth: A Traditional Debate Reviewed. Canadian Journal of Philosophy, suppl. vol. 24: 31-74. 